\title{
EFL Learner's Awareness of Stress-Moving vs. Neutral Suffixes
}

\author{
Zahra Ghorbani Shemshadsara \\ Roudbar Branch, Islamic Azad University \\ E-mail: z.ghorbani1971@yahoo.com
}

Received: June 9, 2011

Accepted: July 12, 2011

Published: December 1, 2011

doi:10.5539/elt.v4n4p146

URL: http://dx.doi.org/10.5539/elt.v4n4p146

This research is sponsored by Roodbar Azad University.

\begin{abstract}
Mastering pronunciation in EFL context, where direct access to native speaker is scarce, is a highly challenging objective for many language students in Iran.

Stress as a suprasegmental feature, more specifically, poses its own problems, specially when suffixes are added to words. There are different types of suffixes, two of which are neutral (with no effect on word stress) and stress-moving (changing stress pattern).

This research study intends to investigate the students awareness of stress patterns when (stress-moving and neutral) suffixes are added to words. Thirty freshmen participated in this research. Their voices are recorded and analyzed. The use of Matched T-test shows that there is a significant difference in the level of difficulty of these two types of suffixes for the learners.
\end{abstract}

Keywords: Pronunciation, Stress-moving suffix, EFL learner, Suprasegmental

\section{Introduction}

The usefulness of teaching pronunciation is a widely debated subject in the language teaching world. Some of the current research studies suggest that teachers can make little or no difference in improving their students' pronunciation. In contrast, there is some research that indicates the teacher can make a noticeable difference if certain aspects of pronunciation such as stress are explicitly taught to the learners. As Richards and Renandya, (2002, p.178) stated:

Irrelevant in the grammar translation approach, pronunciation grew in prominence with the rise of the

Direct Method and Audiolingualism, only to be pushed again to the sidelines with the ascendency of communication Language Teaching (CLT) and the Natural Approach. Today, pronunciation teaching is experiencing a new resurgence, fuelled largely by the increasing awareness of the communicative function of suprasegmental features in spoken discourse.

In structural pedagogy, pronunciation has been viewed as the sum of three components. The components are sounds, stress and rhythm, and intonation. Perhaps it is due to the complexity of these components, that structuralists put forth that in the classroom these components have to be explicated separately; furthermore, the teacher's degree of phonological knowledge may inform the selection in order to achieve success in pronouncing the phonemes accurately (Morley, 1991).

Concurrently, there has been a shift from specific linguistic competencies to broader communicative competencies as goals for teachers and students (Morley, 1991, p.481-520). Morley states the need for the integration of pronunciation with oral communication, a change of emphasis from segmental to suprasegmentals. Research has shown that teaching phonemes isn't enough for intelligibility in communication (Cohen, 1977, p.71-77). With the emphasis on meaningful communication and Morley's premise, that Intelligible pronunciation is an essential component of communication competence' teachers should include pronunciation in their courses and expect students to do well in them.

Kenworthy (1987) also puts forward the concept of 'comfortable intelligibility' as a suitable goal for the majority of learners.

Morley (1991, p.496) supports Kenworthy's view:

The goal of pronunciation should be changed from the attainment of perfect pronunciation to the more 
realistic goals of developing functional intelligibility, communicability, increased self-confidence, the development of speech monitoring abilities and speech modification strategies for use beyond the classroom. The overall aim of these goals is for the learner to develop awareness and monitoring skills that will allow learning opportunities outside the classroom environment.

Morley (1991) states that 'intelligible pronunciation is an essential component of communication competence'.

\section{Why is EFL Pronunciation Teaching Ignored?}

Teaching English pronunciation is still surprisingly and shockingly neglected and /or ignored in many EFL settings including Iran, although the listening and speaking skills are now somewhat included in the syllabus and taught to equip the learner with adequate communicative competence. At the primary, secondary and tertiary level in Iran, an English pronunciation course or English pronunciation as a component is hardly given any considerable place at all. In china, an English phonetics course is simply left to chance or given no room (Cheng, 1998). As in Bangladesh, some teachers in Taiwan might argue that English pronunciation is not important at all, for very few tests would require students to show abilities related to pronunciation or speaking (Lin, Fan and Chen, 1995). Similarly, English pronunciation is arbitrarily overlooked in Thailand (Wei and Zhou, 2002). In Mexico, pronunciation is described as "the Cinderella of language teaching", that means an often low level of emphasis is placed on this very important language skill (Dalton, 2002). It is then evident that teaching EFL pronunciation has little room in the syllabus, material and classroom.

\section{Hypotheses}

1. There is no difference between stress-moving and neutral suffixes in terms of level of difficulty.

2. There is no relationship between performance on stress-moving suffixes and performance on neutral suffixes in terms of reading stress.

\section{Definition of the Key Terms}

Stress: The pronunciation of a word or syllable with more force than the surrounding words or syllables. A stressed word or syllable is produced by using more air from the lungs (Richards, Platt, Longman, 1992).

Stress-moving suffixes: They are the suffixes which change the pattern of stress in a word when added, such as -ic. For example, in the word economy stress is on the second syllable. After adding the suffix -ic in the word economic, stress moves to the third syllable.

Neutral suffixes: There are some suffixes that make no changes in the place of stress when added to the words. For example, happy + ness $=$ happiness $($ Roach, 1992)

\section{Stress}

\subsection{The nature of stress}

Phonetically speaking, we can study stress from the point of view of production and of perception. Although they are closely related, they are not identical. The production of stress is generally believed to depend on the speaker using more muscular energy than is used for unstressed syllables. From perceptual point of view, all stressed syllables have one characteristic in common, and that is called prominence. Stressed syllables are recognized as stressed because they are more prominent than unstressed syllables (Peter Roach, 2004).

Phonologically speaking, we study the abstract side of the sounds of language. In every language, we find that there are restrictions on the sequences of phonemes that are used. For example, no English word begins with the consonant sequence /zbf/ and no words end with the sequence /ah/. In phonology we must try to analyze what the restrictions and regularities are in particular language, and it is usually found helpful to do this by studying the syllables of language.

According to Peter Roach (2004) many significant sound contrasts are not the result of differences between phonemes. For example, stress is important: when the word "import" is pronounced with the first syllable sounding stronger than the second, English speakers hear it as a noun, whereas when the second syllable is stronger, the word is heard as a verb. Intonation is also important: if the word "right" is said with the pitch of voice rising, it is likely to be heard as a question or an invitation to a speaker to continue, while falling pitch is more likely to be heard as confirmation or agreement. These examples show sound contrast that extend over several segments, and such contrasts are called suprasegmental.

According to Peter Roach (2004) there are three levels of stress including primary, secondary, and unstressed. The primary stress results from pitch movement or tone that gives the strongest type of stress; that is why it is also called tonic strong stress. For example, the third syllable of the word 'economical' has primary stress. The secondary stress, 
on the other hand, is weaker than the primary stress and it is transcribed with low mark as indicated in the first syllable of the word economical. The third level of stress cannot be felt that much in a word; that is why it is called unstressed syllable. The second, the forth and the fifth syllable in the word economical all have weak stress.

\subsection{Complex word stress}

Complex words are of two major types. First, there are words made of a basic stem, word with the addition of an affix. For example, good + ness= goodness. Second, there are compound words, which are made of two independent words, for example, ice+cream= ice-cream.

\subsection{Affixes}

Affixes are of two kinds that play an important role in place of stress. They are called prefixes and suffixes. The former comes before the stem and the latter comes after the stem. Affixes have one of the following effects on word stress.

i) The affix itself receives the primary stress (e.g. "semi + circle")

ii) The word is stressed just as if the affix was not there ('pleasant', 'unpleasant')

iii) The stress remains on the stem; not the affix, but is shifted to a different syllable (e.g. magnet "magnetic").

\subsection{Suffixes and stress placement in English}

There are different kinds of suffixes three of which are stress-moving, stress-carrying, and neutral, Peter Roach (2004, p.96) stated:

If the stem consists of more than one syllable, there will be a secondary stress on one of the syllables of the stem. This cannot fall on the last syllable of the stem, rather it moves to an earlier syllable. For example, in Japan the primary stress is on the last syllable, but when we add the stress-carrying suffix -ese the primary stress is on the suffix and the secondary stress is placed on the first: Japanese. However, suffixes like able, age, al, ful, ing and ish do not change the place of stress if they attach to words. For example, wonder has primary stress in the first syllable. If we add the suffix -ful to it, the place of stress does not change like wonderful.

\subsection{Stress in the Persian language}

\subsubsection{Stress or accent}

Stress is usually defined as the degree of force with which a word or syllable is uttered. It involves a strong force of exhalation which consequently gives the objective impression of loudness (Keshavarz, 1997). According to Peter Roach (2004) syllabic prominence is achieved by the combined effect of loudness, pitch, quality of the vowels.

In English phonology, syllables of more prominence are normally referred to as stressed syllables. This is, perhaps, because the feature of intensity plays a greater role in achieving prominence in English syllables. This type of accent is termed accent of intensity by some scholars.

Khanlari (1969) believe that in the accented syllables in Persian, the rise in the pitch is much more significant than other features. This kind of accent is considered accent of height.

\subsubsection{Degrees of stress}

Towhidi (1974, p.105-106) considers five degrees of prominence for Persian including strong accent, primary accent, secondary accent, stressed, and weak. The prominence of certain syllables is primarily due to stress and length, with the possible aid of qualifying features but with no concomitant clearly perceivable pitch variations. Wherever a syllable is made prominent in this manner, it is said to be stressed, but if the prominence of a syllable is achieved by the combined effect of stress, length and pitch, that syllable is said to be accented. Such a syllable may have a 'strong', 'primary', or a 'secondary' accent.

Ferguson (1957), however, highlights the fact that only strong vs. weak stress can be significant at word level in Persian.

\subsubsection{Word Accent in Persian}

Ferguson (1957, p.125) proposes that "a Persian word pronounced in isolation has one syllable of heavier accent than the other." When the word is used in sentence, usually the same syllable is accented or word has no accented syllable at all. The syllable on which the accent falls when a given word is uttered in isolation is said to have 'inherent' or 'potential' accent, or simply the word stress. It must be noted that this concept of word accent is essentially morphological. A statement of the type 'The word X in Persian has stress on the third syllable means in effect that the word $\mathrm{X}$ has two alternates, one with accent on the third syllable, one with no accent at all. If the word occurs with the accent on any other syllable, this indicates the presence of an additional morpheme of stress shift. 
According to Ferguson, Iranian learner's mother tongue is syllable-timed whereas English is stress-timed.

\section{Can Pronunciation Be Taught?}

The usefulness of teaching pronunciation is a widely debated subject in the language teaching world. Some of the current research would suggest that teachers can make little or no difference in improving their students' pronunciation. In contrast, there is research that indicates that the teacher can make a noticeable difference if certain criteria, such as the teaching of suprasegmentals are fulfilled.

If the above views indicate the split in opinion about the teaching of pronunciation, can pronunciation be successfully taught, and if so, what are the pedagogical implications for the classroom teacher and the learner? This article, in light of the current research and opinions, asks the question 'Is it reasonable to expect all students to do well in pronouncing words?

Two basic assumptions against the explicit teaching of pronunciation were emerged from the notion of the 'Critical Period Hypothesis 'and Krashen's Input Hypothesis. The former highlights the fact that after the age of puberty, it is impossible to acquire native like pronunciation. Krashen (1982) also emphasizes acquisition not learning.

A lot of studies have supported the notion that children do better than adults in learning the pronunciation of a second language. Such studies, however, fail to prove that it is impossible for adult to acquire native like pronunciation.

Joann Ken worthy (1990) put more emphasis on teacher's role in term of teaching pronunciation. According to ken worthy, the first step is to help learners pricier sounds correctly, that is, in the early stage of learning English language, learners have tendency to hear their native sounds.

A teacher should make sourer if their learners follow an appropriate procedure for acquiring sounds.

The teacher also can help learners in pronouncing English sounds that are not exist in other languages. Learners may be proficient in imitating some new sounds, if they can't the teacher should provide them with some techniques to help them to overcome the problems.

Furthermore, teacher should tell the learners how they are doing. In other words, the teacher has to provide them with feedback because if the learners pronounce some sounds inaccurately, they may fossilize due to overdoing.

\section{Factors Affecting the Pronunciation of EFL learners}

\subsection{The native language factor}

Needless to say, learners of a language speak the target language in a different way: sometimes slightly different and sometimes highly different than the native speakers' do, which we call "foreign accent", the nature of which is determined to a large extend by a learner's native language. This is known as mother tongue interference. That is to say, every language in the world has different varieties and different accents. Therefore, the way we speak is a part of our identity, that is, phonemic difference between language cause a target language which will be spoken with a foreign accent. As a result, there may not be any difference in the pronunciation of [I] and [i], and then a foreign accent carries the sound characteristics of the learners' native language. As known, a language is a part of a culture, thus it is inevitable that there must be mother tongue interference, which is native language influence, in the pronunciation of the target language. This view had been endorsed by Whorfian Hypothesis. According to Sapir and Whorf, peoples' view of world influences their language and also people adopt the view of the world around them through the experience and categories of their language. As a user of Turkish language, we have difficulty in some English words and sounds which are not found in our native language. For example, $/ \theta /$ and $/ \partial /$ sounds do not exist in Turkish, and that is why Turkish learners encounter pronunciation difficulties with the words that include those sounds and thus never obtain a native-like accent, so they produce those sound under the influence of their mother tongue.

\subsection{The age factor}

This is one of the most important factors in the learning of the pronunciation of a foreign language. We can say that if someone pronounces a second language with a native-like accent, $\mathrm{s} / \mathrm{he}$ must have probably started to learn it during their childhood. For instance, children of immigrants may be given as an example. Since these children start their second language learning process in target language speaking people environment, they have more advantages than the children who try to learn the target language in their motherlands because there are indispensable differences between the language a group uses and the language of mainstream classrooms and workplaces. At the same time, if young children are exposed to more than one language before the age of puberty, they seem to acquire all languages equally well since it has been claimed that children are better at learning than adults. As Krashen (1988, p.43) mentioned, acquirers who begin to exposure to a second language during childhood generally achieve higher second 
language proficiency than those beginning as adults. He also stated that lateralization may even be completed by age 4, not by puberty.

\subsection{The amount of exposure}

Another factor is the amount of exposure to the practice of English. English is not only used in the classroom environment. We can handle this subject from the point of view whether the learner has been living in a country where English has been spoken or not. If the learners have been living in an English-speaking country or community, or a country where English is the second language, then the learners will have many opportunities to listen to and use the target language; that is they will be surrounded by the target language. But, on the contrary, if the learners have been living in a non-English speaking country, like Turkey, there will be no advantage for them. So these learners will only be exposed to focused-listening, so they will have no chance or opportunity to use the target language in a real environment.

It must not be forgotten that there are many people who live in an English-speaking country, but spend much of their time in a non-English speaking environment, may be any other language in spoken at home or outside. For this reason, it is not merely exposure that matters, but how the learners respond to opportunities. Briefly, Kenworthy (1987, p.6) mentions that exposure can be a contributory factor, but it cannot be a whole and necessary factor for the development of pronunciation. If a learner is aware of the necessity of being exposed to the target language, s/he should make use of its opportunities. If the learner does that, $\mathrm{s} / \mathrm{he}$ will be more successful in case of improving his/ her pronunciation. The best ways of being exposed would be native speakers, videos shows, films, CDs, radio or TV programs, computer assisted language teaching programs, and etc.

\subsection{Motivation}

If the learners are highly motivated to have a better pronunciation, they can develop a concern for pronunciation, and become more eager to take part in the activities and pay more attention to discriminate the sounds of the target language, and they try to produce better utterances. Motivation can be the key to learn the target language, and they try to produce better sounds. Here it must be pointed out what the motivation is and how the learners will be motivated. According to Brown (1997, p.114-115) the motivation is thought of as an inner drive, impulse, emotion, or desire that moves one to a particular action. He also stated that learning a foreign language requires some of all three levels of motivation which can be global, situational, or task- oriented. For example, a learner may possess high global motivation but task motivation on the written mode of the language.

On the one hand, some factors such as intelligence, aptitude, and self-confidence have much contribution to the formation of motivation. For example, to motivate the less intelligent people will be more difficult than the intelligent ones because these people cannot appeal to their needs. Motivation, of course, is a number of different kinds of attitudes and can be divided into two basic types: instrumental and integrative motivation (Brown, 1997, p.115-117). First one refers to instrumental goals such as furthering a career, reading some kinds of materials, translation, etc. an integrative motivation is the one which is employed when the learners want themselves to be in the culture of the second language group, to identify themselves with and become part of the society.

\section{Method}

Thirty freshmen at Roodbar Azad University majoring in English teaching participate in this research. Two lists of words including main words as the first list and the same words with suffixes as the second list are selected. The second list included words with both stress-moving and neutral suffixes in random order. Afterward, the subjects were asked to read the first words in each list while their voices are recorded. This was the procedure for the rest of the words in the lists. Then the participants were scored for their performance on the two types of suffixes and two scores were assigned to each subject: one for reading words with stress-moving and the other for reading words with neutral suffixes. After that Matched T-test is used to show if there is a significant difference in the level of difficulty of these two types of suffixes for the learners.

\section{Data Analysis}

This study was planned to investigate the EFL Learner's awareness and competence in placing stress in words as different suffixes are added. These suffixes have different effects on stress patterns: stress-moving suffixes move the stress forward while neutral suffixes do not change the place of stress in words.

The descriptive table displays the mean, sample size, standard deviation, and standard error for both groups. Across all 30 subjects, when stress-moving and neutral suffixes are added to words, for neutral suffix, the average is 7.7000 and for stress moving 5.0833 .

The subjects clearly performed weakly over the course of the study; on average, about 2.6167 points. The standard 
deviations for stress-moving and neutral suffixes reveal that subjects were more variable with respect to Stress moving than to Neutral suffixes.

At .897, the correlation between the stress-moving and neutral suffixes is statistically significant. In other words, the Pearson correlation between the stress-moving and neutral suffixes measurements is .897 , almost a perfect correlation.

The Mean Column in the paired-samples t-test displays the average difference between the stress-moving and neutral suffixes measurements. The Std. Error Mean column provides an index of the variability one can expect in repeated random samples of 30 subjects similar to the ones in this study. The $95 \%$ Confidence Interval of the Difference provides an estimate of the boundaries between which the true mean difference lies in $95 \%$ of all possible random sample of 30 subjects similar to the ones participating in this study. The $t$ statistic is obtained by dividing the mean difference by its standard error. The Sig. (2-tailed) column displays the probability of obtaining a $t$ statistic whose absolute value is equal to or greater than the obtained $t$ statistic.

Since the significance value for change in stress pattern is less than 0.05 , it can be concluded that the average decrease of 2.61667 points in scores of the two types of tests administered is not due to chance variation, and can be attributed to the type of the stress pattern under examination.

\section{Conclusion}

This research was conducted to examine the amount of awareness and skill in pronouncing two types of words: words with stress moving suffix and words with neutral suffix. The result showed that stress-moving suffixes are more difficult to learn than neutral suffixes.

As a result, it is suggested that this feature of stress pattern in the English language be explicitly taught and practiced in the classroom. Otherwise, the learners may not notice such delicate differences in stress patterns of words due to addition of stress-moving suffixes.

Also, as far as research on pronunciation is concerned, the present study can stimulate more investigations on similar problems at both segmental and suprasegmental levels of pronunciation in EFL classes. For instance, some interlanguage studies can reveal the pattern of pronunciation development in EFL learners with different L1 backgrounds. Furthermore, there is a need to try different strategies for teaching pronunciation to discover more effective pedagogical tools or means for the learners to promote their pronunciation.

\section{References}

Brown, H. D. (1997). English language teaching in the "post method" era: Toward better diagnosis, treatment, and assessment. PASAA, 27, 1-11

Cheng, F. (1998). The teaching of pronunciation to Chinese students of English. English Teaching Forum, Jan-Mar, 1998, 37-39

Cohen, A. (1977). Redundancy as a tool in listening comprehension research and classroom applications. TESOL Quarterly, 16, 1, 71-77

Dalton, D. (2002). Some techniques for teaching pronunciation. [Online] Avaliable: http://itself.Org/Techniques/Dalton_pronunciation (May1, 2002)

Ferguson, A. C. (1957). Word stress in Persian language. New York: Linguistic Society of America.

Kenworthy, J. (1987). Teaching English pronunciation. London: Longman.

Keshavarz, M. H. (2005). A practical course of English phonetics and phonology. Tehran, SAMT.

Khanlari, P. (1969). History of Persian language, Vol. 1. Tehran: Bonyad-e Farhang-e Iran.

Krashen, S. (1982). Accounting for child-adult differences in second language rate and attainment. In S. Krashen, R.C. Scarcella, \& M.H. Long (Eds.), Issues in second language research. Rowley, MA: Newbury House. pp. $161-172$

Krashen, S. (1988). Second language acquisition and second language learning. Prentice Hall International (UK) Ltd.

Morley, J. (1991). The pronunciation component in teaching English to speakers of other languages. TESOL Quarterly, 25, 151-174

Richard \& Renandya, J. W. (2002). Methodology in language teaching. Cambridge: Cambridge University Press.

Richard, J., \& Platt, J. (1992). Longman Dictionary of language teaching and applied linguistics. London: Longman 
Group UK Limited.

Roach, P. (2004). English Phonetics and phonology. Cambridge: Cambridge University Press.

Towhidi, S. (1974). Studies in the Phonetics and Phonology of Modern Persian: Intonation and Related Features. Hamburg: Helmut Buske Verrlag.

Table 1. The scores for stress-moving vs. neutral suffixes (The information elicited by reading aloud test administered to 30 subjects is displayed in the table below.)

\begin{tabular}{|c|c|c|}
\hline Subjects & Natural suffixes & Stress-moving \\
\hline 1 & 9.5 & 7 \\
\hline 2 & 9.5 & 6 \\
\hline 3 & 9.5 & 6 \\
\hline 4 & 9 & 7 \\
\hline 5 & 9 & 7 \\
\hline 6 & 9 & 6 \\
\hline 7 & 9 & 7.5 \\
\hline 8 & 8.5 & 6 \\
\hline 9 & 8.5 & 6.5 \\
\hline 10 & 8.5 & 5 \\
\hline 11 & 8.5 & 5.5 \\
\hline 12 & 8.5 & 6 \\
\hline 13 & 8 & 5 \\
\hline 14 & 8 & 6 \\
\hline 15 & 8 & 6 \\
\hline 16 & 8 & 6.5 \\
\hline 17 & 8 & 4 \\
\hline 18 & 8 & 5 \\
\hline 19 & 8 & 5.5 \\
\hline 20 & 7.5 & 4 \\
\hline 21 & 7.5 & 5 \\
\hline 22 & 7.5 & 5 \\
\hline 23 & 6.5 & 3.5 \\
\hline 24 & 6.5 & 5 \\
\hline 25 & 6.5 & 3 \\
\hline 26 & 6.5 & 4 \\
\hline 27 & 5.5 & 2.5 \\
\hline 28 & 5 & 2 \\
\hline 29 & 5 & 3 \\
\hline 30 & 4 & 2 \\
\hline
\end{tabular}


Table 2. Paired Samples Statistics(The results of the data analysis of the two paired samples test are displayed below.)

\begin{tabular}{|l|l|l|l|l|}
\hline & Mean & N & $\begin{array}{l}\text { Std. } \\
\text { Deviation }\end{array}$ & $\begin{array}{l}\text { Std. Error } \\
\text { Mean }\end{array}$ \\
\hline Pair 1 Neutral suffixes & 7.7000 & 30 & 1.42997 & .26108 \\
Stress moving & 5.0833 & 30 & 1.52611 & .27863 \\
\hline
\end{tabular}

Table 3. Paired Samples Correlations

\begin{tabular}{|l|l|l|l|}
\hline & $\mathrm{N}$ & Correlation & Sig. \\
\hline $\begin{array}{l}\text { Pair 1 Neutral suffixes \& } \\
\text { Stress moving }\end{array}$ & 30 & .897 & .000 \\
\hline
\end{tabular}

Table 4. Paired Sample Test

\begin{tabular}{|c|c|c|c|c|c|c|c|c|}
\hline & \multicolumn{5}{|c|}{ Paired Differences } & \multirow{3}{*}{$\mathrm{t}$} & \multirow{3}{*}{ df } & \multirow{3}{*}{$\operatorname{Sig}$ (2-tailed) } \\
\hline & \multirow[t]{2}{*}{ Mean } & \multirow[t]{2}{*}{$\begin{array}{l}\text { Std. } \\
\text { Deviation }\end{array}$} & \multirow{2}{*}{$\begin{array}{l}\text { Std. } \\
\text { Error } \\
\text { Mean }\end{array}$} & \multicolumn{2}{|c|}{$\begin{array}{l}95 \% \text { Confidence Interval } \\
\text { of the Difference }\end{array}$} & & & \\
\hline & & & & Lower & Upper & & & \\
\hline $\begin{array}{l}\text { Pair } 1 \text { Neutral } \\
\text { suffixes- } \\
\text { Stress moving }\end{array}$ & 2.61667 & .67828 & .12384 & 2.36339 & 2.86994 & 21.130 & 29 & .000 \\
\hline
\end{tabular}

\section{Appendix}

Stress-Moving suffixes

\begin{tabular}{|c|c|c|c|c|}
\hline 1. economical & 2. Reflexive & 3. Publicity & 4. Advantageous & 5. Scientific \\
\hline 6. Biological & 7. photography & 8. sympathetic & 9. volunteer & 10. Proverbial \\
\hline 11. Climatic & 12. injurious & 13. tranquility & 14. perfection & 15. electronic \\
\hline 16. Exposition & 17. Realization & 18. Schematic & 19. Temptation & 20. governmental \\
\hline \multicolumn{5}{|c|}{ Neutral Suffixes } \\
\hline 1. comfortable & 2. Wonderful & 3. Amazing & 4. Powerless & 5. Glorify \\
\hline 6. otherwise & 7. Funny & 8. happiness & 9. Reasonable & 10. devilish \\
\hline 11. hurriedly & 12. Punishment & 13. Poisonous & 14. Glorify & 15. emptiness \\
\hline 16. Emotional & 17. Embarrassment & 18. Favorable & 19. Rational & 20. scarcely \\
\hline
\end{tabular}

